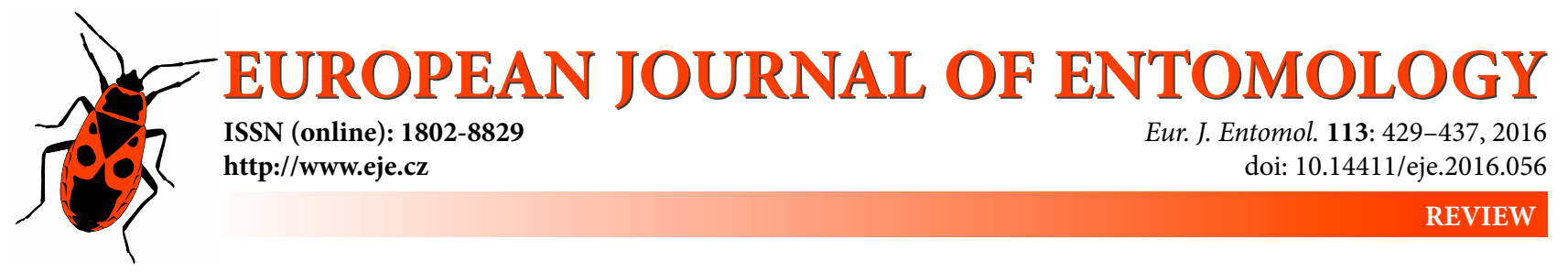

\title{
Implications of insect responses to supernormal visual releasing stimuli in intersexual communication and flower-visiting behaviour: A review
}

\author{
KARL KRAL \\ Institute of Zoology, Karl-Franzens University Graz, Universitaetsplatz 2, A-8010 Graz, Austria; \\ e-mails: karlkral@aon.at, karl.kral@uni-graz.at
}

Key words. Insects, butterflies, bumblebees, visual stimuli, pollinators, mating, foraging, orchid mimicry, food reward, floral size, floral symmetry, ultraviolet signals

\begin{abstract}
Animals, including human beings, tend to respond more strongly to stimuli that are associated with the highest relative rewards. This applies not only to food rewards but also to reproductive success. In the present review article this issue is discussed for insects in connection with intersexual communication and flower-visiting behaviour. Implications of the preference for supernormal visual releasing stimuli are examined from a sensory and evolutionary perspective, including a consideration of the choice of potential mates and recognition of the most rewarding flowers.
\end{abstract}

\section{INTRODUCTION}

External stimuli that serve as signals that elicit neural and motor responses resulting in specific behaviours are termed "releasers" or "releasing stimuli" (Russell, 1943; Immelmann \& Beer, 1992; Barrows, 2011). Releasing stimuli are often considered to be simple, with one or at most a few specific features, such as colour, size, movement pattern or shape of a biologically important animal or object. The stimuli need not arise from a single source. They can also be configurational, made up of multiple features that in combination stimulate behavioural responses. This complexity can decrease the likelihood of maladaptive behaviour, because deviations from the stimulus can prevent the specific behaviour.

The entire sequence of neural responses elicited by a stimulus is not dependent solely upon the external stimulus. The internal physiological state of the insect also determines whether or not the motor patterns are released. The relationship between these factors ultimately determines the response to a stimulus. For instance, depending upon their sexual readiness or need to forage, insects may more readily respond to stimuli which deviate somewhat from typical stimuli. The significance of such adaptive plasticity lies in its ability to maximise the perception of biologically relevant stimuli (Tinbergen, 1948, 1951). When features of releasing stimuli (e.g. brightness or colour saturation) are enhanced beyond their average levels by natural or artificial factors, they can be more effective in eliciting a specific behaviour than the signals for which an insect is genetically or phenotypically adapted. This phenomenon was originally described in early ethological literature (Tinbergen, 1948, 1951), and a variety of noteworthy examples in insects can be found in both older and more recent literature. The aim of the present article is to review this literature with regard to the significance of insect responses to supernormal visual releasing stimuli, using as examples sexual communication in butterflies and some other insect species, and foraging behaviour in flower-visiting insects.

\section{INTERSEXUAL COMMUNICATION}

Butterflies are convenient model organisms for such studies due to their conspicuous appearance and slow movement through the landscape, which makes them relatively easy to observe. It should be kept in mind that despite interspecific differences, most butterflies are diurnal and primarily visual communicators, although odour can also be important for communication. However, visual cues may be more robust than odour cues because they are not affected by wind or temperature. The most important visual cues for these insects are the colour, including ultraviolet (UV), displays of their flapping wings, which play a role in communication, camouflage and warning. There is a large body of information on sexual communication in butterflies in the literature (e.g. Rutowski, 1977; Silberglied, 1977, 1984; Meyer-Rochow \& Järvilehto, 1997; Rutowski et al., 2001, 2007; Wiklund, 2003; Kinoshita et al., 2008; Imafuku \& Kitamura, 2015). Sexually active male butterflies search for mates by flying around or by waiting on perches that females can be expected to pass and be easily detected. However, the effective visual range of 


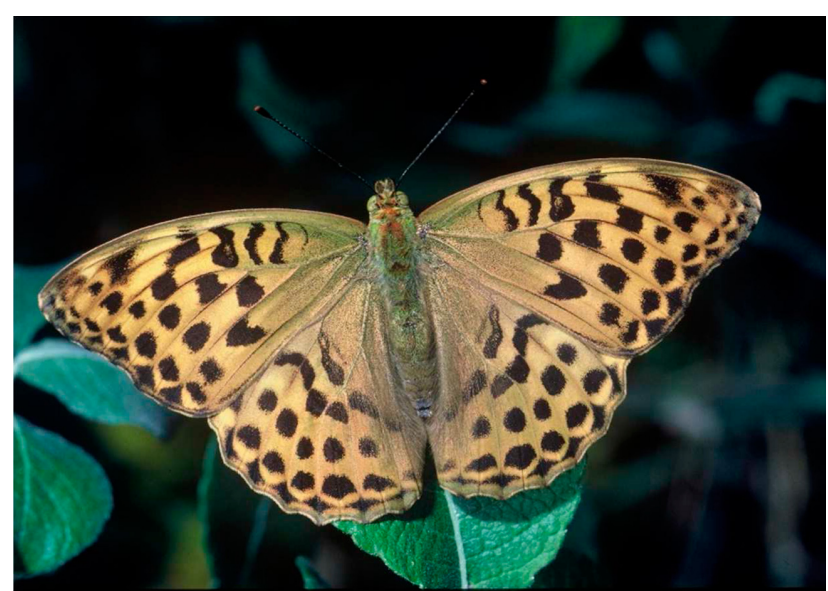

Fig. 1. Female of the silver-washed fritillary butterfly Argynnis paphia (Linnaeus, 1758). Note the coloration of the upper side of the wings: A light orange-brown with dark brown to black markings and some areas of grey-green to olive-green. The underside of the hind wings (not shown) is greenish with "washed" (rather than well-defined) silver bands, hence the common name of the species. With a wingspan of around 55 to $65 \mathrm{~mm}, A$. paphia is one of the largest European butterflies. (Photograph by Eddie John, used with kind permission.)

detection for a potential mate may be limited to a few metres. As soon as a sexually active male detects an object that resembles a receptive female in terms of colour and movement, the male persistently pursues it. For a definitive determination of a potential mate, it is necessary for the male to approach to within a few centimetres, when wing details and odour assume an important role. The visual system of the butterfly is well adapted to these tasks. The two spherical compound eyes are of apposition type and have a large visual field, high spatial acuity and contrast sensitivity (Land, 1997; Merry et al., 2006), a spectral sensitivity ranging from ultraviolet (UV) to red wavelengths (e.g. Arikawa \& Uchiyama, 1996; Stavenga et al., 2001; Zaccardi et al., 2006; Koshitaka et al., 2008) and high sensitivity to movement (Rutowski \& Warrant, 2002).

Male butterflies may respond more strongly to brightly coloured models than typically coloured conspecific females (Magnus, 1958). For example, males of the silverwashed fritillary butterfly Argynnis paphia (family Nymphalidae) are more strongly attracted to monochromatic orange paper models than to conspecific females, with orange-brown wings patterned with dark brown to black markings (see Fig. 1). In A. paphia, the flapping frequency of the wings is usually about 8 to $10 \mathrm{~Hz}$. However, Magnus (1958) records males responding more strongly to artificial stimuli with up and down strokes of $20 \mathrm{~Hz}$ and even flickering frequencies of up to $140 \mathrm{~Hz}$. Here the artificial stimuli were produced first by a motor-driven carousel and subsequently by a rotating spool. The carousel arms supported either a flapping butterfly model or revolving cylinders with alternating colours; whereas the spool consisted of alternating bands of colour (see also schematic drawings on page 260 of Matthews \& Matthews, 1978). In butterflies, as in other insect orders, the size of the female can also serve as an important visual releasing stimulus. Magnus (1958) shows that males of $A$. paphia follow conspecific females (wing area of around $20 \mathrm{~cm}^{2}$ ) less frequently than models with wings two to four times larger (wing area of up to $88 \mathrm{~cm}^{2}$ ). However, this occurred only when the movement of the models somewhat resembled that of a conspecific female. The shape of the models did not play a role; models with circular, triangular or square wing shapes were as attractive as a conspecific female. The males seemed to be unresponsive to all features except for the fluttering patch of colour. The results for A. paphia are basically consistent with those for other species of butterflies (Lundgren, 1977; Matthews \& Matthews, 1978, p. 41, 259). When a male is within a few centimetres of a female, monochromatic colour signals no longer play a role, and the releasing stimuli are colour patterns, sexual odour and finally tactile cues.

While the findings of Magnus (1958) are specifically for male butterflies as signal receivers, the wing coloration of male butterflies can also serve as a signal to females in mating behaviour. For example, the role of male coloration in intersexual signalling studied by Rutowski (2003) and White et al. (2015). In addition, UV markings can play an important role. In the butterfly Hypolimnas bolina (family Nymphalidae) the flashing UV signals from the upper surface of the four wings of courting males may act as optical stimuli for females, allowing a couple to find optimal positions relative to each other and in stimulating a female's readiness to mate. The optimal position is when the male flies just below the female (Kemp, 2007; Rutowski et al., 2007; White et al., 2015). White and co-workers have shown that this position permits the males to enhance the flashing effect by increasing the brightness and wing area visible while simultaneously minimising the amount of time during each wing beat cycle in which the UV signal can be seen. H. bolina behaved similarly to A. paphia in the model experiments of Magnus (1958), who found that enhanced surface coloration and wingbeat frequency of female models can serve as exaggerated stimuli to courting males.

Based on his experiments with models, Magnus (1958) concludes that for a male of $A$. paphia, the ideal female would be up to four times larger, with pure orange wings and a wing flickering speed at the maximum detectable rate of around $140 \mathrm{~Hz}$. It is clear that such exaggerated releasing stimuli do not reflect reality in the natural world. For example, in terms of physics, such extremely fast wing movements would be impossible in butterflies. However, it is interesting that the range of temporal resolution of the compound eyes of male A. paphia, extends up to 140 images per second (Matthews \& Matthews, 1978, p. 259; see also Rutowski, 2003). It is also noteworthy that a wing area four times larger than that of the male would occupy the entire frontal visual field of the male, at the distance at which the models were presented. Hence, it appears that the visual system of male $A$. paphia can perceive a flickering orange stimulus up to the maximum perceptual range. This may also apply to other mating butterflies, as indicated for H. bolina (Rutowski, 2003; White et al., 2015). It means that the response to visual releasing signals is not 


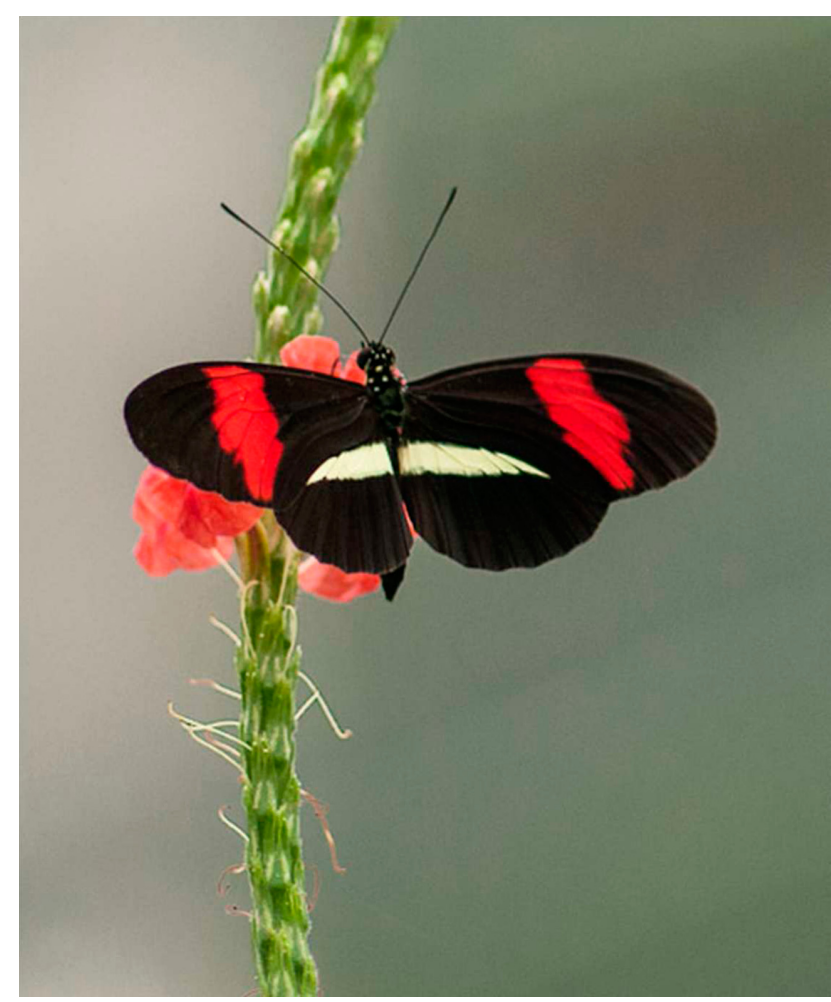

Fig. 2. Photograph of Central American postman Heliconius erato petiverana (Doubleday, 1847) from Costa Rica. The black elongated wings can have various areas of bright red or orange coloration The wingspan is around 60 to $80 \mathrm{~mm}$. For information about the evolution of the species, see e.g. Brown (1981) and Brower (1994). (C) 2012 Harry Hull III, San Vito Bird Club, http://sanvitobirdclub. org, used with kind permission).

restricted to typical natural stimuli, but can also include supernormal stimuli. This implies a larger perceptual range than is usually required, which could have the evolutionary advantage of permitting responses to relatively rapid quantitative changes in releasing stimuli, thus facilitating adaptation. For example, deviations in the structural coloration of butterfly wings can occur many times faster (Brakefield \& French, 1999; Wasik et al., 2014; see also Meyer-Rochow \& Järvilehto, 1997) than corresponding morphological modifications in the properties of the visual system.

In considering the role of wing coloration in intersexual communication in butterflies, it should be kept in mind that the solid orange of A. paphia and red of Heliconius erato females (Magnus, 1958; Matthews \& Matthews, 1978), which serve as strong releasing stimuli, can be regarded as a result of an evolutionary compromise (see Matthews \& Matthews, 1978, p. 41). Due to predation pressure, particularly on females searching for oviposition sites, the orange and red signals can be expected to be limited by natural selection to marks, spots and stripes (see Figs 1 and 2). In many species, UV markings on the wings are also important for intersexual communication. As recently shown by White et al. (2015), the maximally bright UV reflectance of white spots surrounded by shimmering blue scales on the black upper side of the wings of courting $H$. bolina males can be seen only from a very restricted angle. This has the advantage that the UV pattern of the males is clearly visible to $H$. bolina females, but not to avian predators. It is suggested that the phenomenon of directionality of UV signals may also be important for many other species of butterflies with prominent UV patterns on their wings (e.g. Eguchi \& Meyer-Rochow, 1983; Meyer-Rochow, 1991; Rutowski et al., 2007). An interesting example of UV signal adaptation is described for the butterfly Pieris napi (family Pieridae) by Meyer-Rochow \& Järvilehto (1997), the dorsal wing surfaces of the females of which at Arctic latitudes exhibit significantly stronger UV reflectivity than those of conspecific females at lower latitudes. They suggest that this above-average reflectivity may serve to compensate for the reduced UV radiation at Arctic latitudes resulting from the lower angle of the sun, thus enabling Arctic P. napi males to detect these signals, even if the UV-sensitivity of their compound eyes is similar to that of males at lower latitudes. From an evolutionary perspective, this may indicate that wing coloration can adapt more readily than the sensitivity of the eyes. Wing polarisation could also serve as a visual signal, as indicated by studies of some neotropical nymphalid species (e.g. Sweeney et al., 2003; Douglas et al., 2007). In light of the fact that the preference for supernormal visual stimuli could potentially result in an evolutionary trap, it seems likely that the interaction of a combination of visual signals could play an important role in ensuring successful intersexual communication.

Research concerning preferences for supernormal visual releasing stimuli in sexual communication is not limited to butterflies. Such behaviour also occurs in flies and beetles. For instance, Vogel (1957) reports that the courtship behaviour of male houseflies Musca domestica (family Muscidae) is optimally released by an artificial object two to three times the size of an average female. The male flies are attracted to both two- and three-dimensional models. However, three-dimensional models are more effective. If the oversized models are moved at a velocity of up to $4.2 \mathrm{~m} /$ sec away from the males or flicker, the stimulus results in a stronger response (Vogel, 1957). In the common flesh fly Sarcophaga carnaria (family Sarcophagidae), males follow oversized models more frequently than models closer to the natural size of females (Vogel, 1958). In this context, it should be noted that flies often pursue target objects of a wide range of sizes, even if they are larger than usual (Boeddeker et al., 2003). Recent studies of mate recognition behaviour in the fruit fly Drosophila melanogaster (family Drosophilidae) using robotic fly models of various sizes, shapes and speeds reveal, however, that males prefer models close to the size of females, and are less likely to pursue larger models (Agrawal et al., 2014). It is possible that size as a feature plays varying roles in intersexual communication in different dipteran families. In the case of the robber fly Mallophora ruficauda (family Asilidae), on the other hand, courtship behaviour is elicited not only by oversized models but also, as in the case of $A$. paphia, by models that are atypical of the female colour pattern (Tricca \& Trujillo-Cenóz, 1980). Since large objects can be seen at greater distances, an important experimental control is to present both oversized objects and objects of natural size at 
the same distance from the male, to facilitate a direct size comparison. Based on the literature, this procedure was always followed.

A well-known example of supernormal stimuli in sexual communication is provided by the Australian jewel beetle Julodimorpha bakewelli (family Buprestidae), the males of which are recorded attempting to copulate with discarded beer bottles (Gwynne \& Rentz, 1983). These researchers found that tubercles around the base of the shiny brown glass bottles produced light reflections resembling the shape and colour of an aggregation of female beetles (Gwynne \& Rentz, 1983; Hawkeswood, 2005). According to Schlaepfer et al. (2002), these bottles constitute an evolutionary trap for jewel beetle males, because previously reliable mate-related cues may no longer be associated with adaptive outcomes. This could also be the case for other artificial stimuli, such as electric light sources that serve as exaggerated stimuli for positively phototactic moths. One reason for this could be the UV radiation produced by artificial light sources, and the low UV stimulus threshold of moths (Cowan \& Gries, 2009). Similarly, the high level of linearly polarised sunlight reflected from black plastic foil, glass panes, puddles of black oil or wet asphalt streets can trigger egg-laying or foraging behaviour in aquatic insects such as dragonflies, mayflies, water bugs and water beetles. Polarotactic insects seem to choose such artificial "visual traps" over natural bodies of water due to their stronger releasing signals, which provide aboveaverage stimuli, even though landing could prove fatal to the insect (e.g., Bernáth et al., 2001; Horvath et al., 2009). However, the emergence of evolutionary traps in the modern world and the implications for animals (including insects) is still poorly understood, although it has become increasingly important (Robertson et al., 2013; Goodwin et al., 2015).

Intersexual communication signals in insects have also affected the evolution of flowers. This is clearly illustrated in the relationship between orchids and insects. In some orchid flowers, the labellum (see Fig. 3) has evolved in such a way that its colour and/or shape resembles that of a receptive female insect. The advantage for the orchid is that sexually active males are attracted, with the result that the orchids are successfully pollinated. Due to their dependence on specific pollinators, the orchids have evolved signals that serve as strong releasing stimuli (Kullenberg, 1961; Paulus, 1997; Spaethe et al., 2007). Kullenberg (1961) was one of the first to study this phenomenon systematically in many species of the Mediterranean genus Ophrys. For example, in Ophrys apifera, the species name "apifera" means "bee-carrying", referring to the specific adaptation of the labellum of the orchid. Recently, the interaction between sexually active males of the Australian wasp Lissopimpla excelsa (family Ichneumonidae) and the tongue orchid Cryptostylis (family Orchidaceae) has been investigated by Gaskett et al. (2008) and Gaskett (2011). In these studies, the authors confirm that the orchid labellum can effectively mimic crucial features of the female wasp and may serve as an exaggerated visual stimulus for male

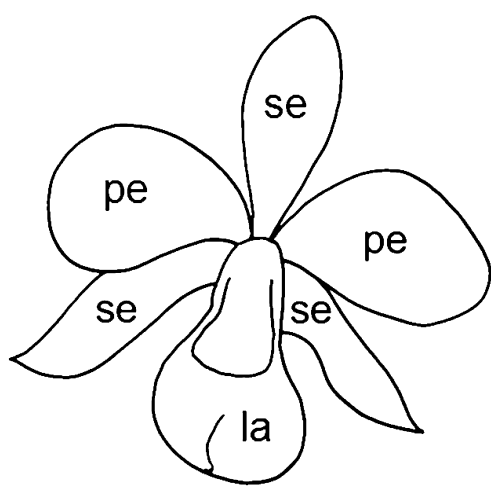

Fig. 3. Schematic drawing of an orchid flower; la - labellum or lip; pe - petalum; se - sepalum. The labellum is a specialised median petal, and can be distinguished from the other petals and sepals by its frequently larger size, irregular shape and bright coloration. In some orchids, the labellum mimics the female of a species of wasp or solitary bee, serving as a supernormal stimulus that attracts males of the species. Orchids have bilaterally symmetrical corollas, usually in the vertical plane.

wasps of the relevant species. After landing on the labellum, the males can ejaculate intensively in pseudo-copulation as a response to the stimuli. Although this is associated with costs in terms of sperm and energy wastage and the risk of predation, which might be expected to select for male avoidance of orchids, the pollination of orchids that stimulate pseudo-copulation by male wasps interestingly is highly successful. Gaskett et al. (2008) attempts to account for the fact that orchid mimicry is sustained despite the cost to the wasps by stating that unmated female wasps are still able to have male offspring. Thus, the female wasps can compensate for the loss of males resulting from orchid mimicry of their intersexual communication signals and at the same time produce further orchid pollinators. In this context, it is important to note that orchids exhibiting such mimicry are usually pollinated by haplodiploid insects with a solitary social system (Hardy, 1994; Gaskett et al., 2008; Gaskett, 2011).

As shown by Bohman et al. (2016), many orchid flowers not only have a labellum of a shape and colour similar to that of a specific female insect, but also have an odour that mimics the female sex pheromones, thus attracting males. One well-described example is the broadlip bird-orchid Chiloglottis trapeziformis (family Orchidaceae), which attracts male thynnine wasps Neozeleboria cryptoides (family Tiphiidae), resulting in successful pollination (Wong \& Schiestl, 2002; see also, de Jager \& Peakall, 2015). It is suggested that the chemical mimicry is an effective longrange attraction, while the visual appearance of the callus structures on the labellum can lead to pseudo-copulation. Sexually active males may respond to orchids that appear to be female wasps, especially when the females have not yet emerged. In fact, the males of these solitary bees respond to the odour of an orchid rather than to the sex pheromones of female bees even when the odours are different (Jersáková et al., 2006). Based on such results it seems likely (as suggested by Vereecken \& Schiestl, 2008) that male insects may respond more readily to unusual odour stimuli, which include components or features that are also 
present in the normally available stimuli, but may be more salient, i.e., easier to detect. The preference of male insects for unusual odour stimuli, for instance, could be a significant factor in signal evolution (Lynn et al., 2005; ten Cate \& Rowe, 2007; Benitez-Vieyra et al., 2009).

What applies to the odour of orchids could in principle also apply to their visual features. The fact that the shape and colour of an orchid labellum, which mimics the body of a female wasp or bee, is often exaggerated and is not necessarily a perfect imitation, similarly indicates that male insects may respond strongly to unusual stimuli or uncommon phenotypes. This may be related to a heightened physiological state of the male (see Introduction) and/ or a lack of receptive females, since females can emerge later than males. However, in this case orchid mimicry also raises the question of whether the males exhibit a strong response to the orchid because it looks like a particularly fertile female or simply because the orchid is easy to detect. If the latter is true, it could be that the male is unable to assess the intensity of the stimulus accurately and consequently does not reject a high intensity stimulus. For instance, the difference in intensity of the stimuli provided by a model and a female insect may be detectable by a human observer but not perceptible to the sensory system of a male insect. Likewise, the relevant sensory and behavioural ecology must be understood before conclusions can be drawn.

\section{FLOWER-VISITING BEHAVIOUR}

Animals, including human beings, tend to respond more strongly to stimuli that are associated with the highest relative rewards (Staddon, 1975; Lea \& Ryan, 2015). This selection strategy, with the general rule "the more, the better", has its roots in resource-scarce environments and is especially apparent when above-average alternatives exist. Reward mechanisms in the brain, such as the activation of dopamine pathways, have evolved which reinforce adaptive behaviour and responses to stimuli that pertain to the greatest biological fitness. This applies not only to food rewards but also to reproductive success as described in the previous section (Chakravarthy \& Booth, 2004; Goodwin et al., 2015). Neural reward mechanisms in insects, for instance in the mushroom bodies, have evolved which may function analogously to those in mammals. In insects, these mechanisms are associated with reward learning behaviour (Perry \& Barron, 2013).

Flower-visiting insects can face the problem that the quality and quantity of food available from flowers is not directly apparent to them (Goulson, 2012). Thus, they may use other easily detectable cues such as size, shape, colour to determine the most rewarding flowers. In bumblebees, if a choice is available, the largest flowers are visited, and otherwise suitable flowers with a smaller corolla may be ignored. Inflorescence size, in terms of the number of flowers per inflorescence, can be another indirect cue that attracts pollinators (Galen \& Newport, 1987; Cresswell \& Galen, 1991; Ohara \& Higashi, 1994). One reason for this selective foraging behaviour may be that flower and inflorescence size are correlated with the quantity and quality of pollen or nectar available. The selection of large flowers may also be reinforced by rapid sensory learning (Menzel \& Erber, 1978; Cresswell \& Galen, 1991). On the other hand, bumblebees may select flowers with a large corolla due to the fact that pollen or nectar can be collected more easily from such flowers. In other words, bumblebees may be attracted to flower morphology that permits the collection of more pollen and nectar (Galen \& Newport, 1987). This could mean that foraging efficiency might be higher for flowers from which food is easier to collect due to a large corolla width, than for flowers with greater amounts of pollen or nectar that are less accessible due to a smaller corolla. However, the interaction of factors may be more complex for other flower-visiting insects than it is for bumblebees, as has been shown using flower models, which reveal that other visual features of flowers, such as UVsignals or corolla shape, can play a role in the selection process. For example, in some cases there can be a strong correlation between corolla shape (e.g. narrow petals or round overlapping petals) and pollen or nectar production (Gómez et al., 2008).

Flower-visiting insects can also be more attracted to symmetrical than to imperfectly symmetrical or asymmetrical corollas (e.g., Dafni et al., 1997). This is particularly pronounced in bumblebees and honeybees, which can perceive two main types of floral symmetry, radial and bilateral. Their stronger response to symmetrical shapes can be reinforced by learning (Giurfa et al., 1996, 1999; Rodriguez et al., 2004). The symmetry of flowers, particularly bilateral symmetry that evolved from the ancestral state of radial symmetry, is often not perfect, as demonstrated by Neal et al. (1998). Such deviations may result from environmental stress and lower fitness of the flowers, which could also be associated with a reduced quantity or quality of nectar or pollen (Møller \& Eriksson, 1994, 1995; Giurfa et al., 1996, 1999). Møller \& Sorci (1998) suggest that the precision of floral symmetry may be positively correlated with food rewards. In field studies, these authors found that perfectly symmetrical models of flowers were more attractive (even though unrewarding) than less symmetrical natural flowers. In this case the real flowers provide average stimuli, whereas the models of flowers provide above-average stimuli. However, not all researchers have found a direct relationship between symmetry and food rewards. For example, Palmer (1996) has discussed why some deviations from morphological symmetry may not be biologically meaningful.

If floral symmetry is important for flower-visiting insects, then their compound eyes can be expected to be adapted to the perception of floral symmetry. This would presuppose neuronal networks that are finely tuned for signals concerning morphological symmetry. In fact, there are many indications in the literature regarding symmetry detectors in the neuronal systems of flower-visiting insects and various possible mechanisms are suggested (e.g., Srinivasan et al., 1993, 1994; Horridge, 1996; Giurfa et al., 1999). Due to the different orientations of contrast boundaries in radially and bilaterally symmetrical flowers, different neuronal 
mechanisms underlying radial and bilateral symmetry detection are expected (Giurfa et al., 1999). However, it is not the case that insects select flowers solely on the basis of their symmetry, or that there is always a positive relationship between floral symmetry and food rewards (Møller \& Eriksson, 1995; Palmer, 1996). It may also be the case that flowers with a more symmetrical pattern are more conspicuous and easier to detect by insects in a natural environment, which often tends to be chaotic and "messily" structured (Enquist \& Arak, 1994; Kenward et al., 2004).

It is unclear to what extent flower-visiting insects can improve their foraging efficiency by using the intensity of floral UV reflectance and patterning to determine the most rewarding flowers. In discrimination experiments in the field, UV reflectance as a visual cue is more difficult to record and quantify than size and shape, since UV signals (and colour signals generally) can vary depending upon lighting and background conditions. It is well-established that many flower-visiting insects are able to perceive and are attracted by UV floral patterns (e.g., Daumer, 1958; Horovitz \& Cohen, 1972; Guldberg \& Atsatt, 1975; Chittka et al., 1994; Dinkel \& Lunau, 2001). For example, the elimination of floral UV reflection can decrease visiting by various species of bees (Johnson \& Andersson, 2002; Welsford \& Johnson, 2012). In addition, Koski \& Ashman (2014) have found that flowers with spatial variation in UV reflectance can be more attractive to bees and syrphid flies than those with uniform UV reflectance. Thus, flower-visiting insects are able to respond to variations in UV floral patterns. However, it remains unclear whether UV reflectance alone can be a direct indicator of the most rewarding flowers. Contrast among other colours is also a possible cue. It should be noted that a study by Chittka et al. (2003) indicates that although bumblebees exhibit colour preferences, they are able to select more rewarding flowers even if these differ somewhat from the preferred colour.

The behaviour of flower-visiting insects is frequently analyzed in terms of time and energy budgets, with regard to foraging efficiency. Heinrich (1979) showed that in bumblebees time can be more important than energy. However, foraging efficiency can be negatively affected by some types of flower. For example, orchid flowers can attract insects with especially large, brightly coloured flowers, even though they contain little or no food (Jersáková, 2012). Among European orchids, lady's slipper orchids Cypripedium calceolus (Orchidaceae) provide a conspicuous example of supernormal visual stimuli. During the flowering period, they are one of the largest flowers in their microhabitat. The brightly coloured slipper flowers, often more than $4 \mathrm{~cm}$ long, attract foraging insects. Due to the smooth surface of the bulbous slipper, insects landing on the edge slip down. Because they are unable to climb up the inside wall, to leave the flower they must pass the stigma and stamens, thus fertilising the flower (Darwin, 1826; Nilsson, 1979). Freshly emerged flower-visiting insects, without previous experience, frequently respond to such visual signals, which might usually be associated with particularly large pollen-filled anthers. However, in- sects that have visited such flowers quickly learn to avoid orchids (Ziegler, 2011), making the orchids dependent on other inexperienced pollinators. The exaggerated signals of the orchids thus serve to attract new pollinators.

\section{CONCLUSION}

From this review of the literature, it can be seen that insect responses to supernormal visual stimuli have a variety of evolutionary implications. Many of the examples cited suggest that for insect intersexual communication and flower-visiting behaviour, to a great extent visual releasing stimuli arise through co-evolution, while at the same time already existing stimuli exert both intra- and interspecific selection pressure. For intersexual communication to be effective, conspecific male and female insects must be able to provide and receive distinctive signals. Likewise, mutual selection pressure is exerted between foraging flowervisiting insects and flowers that are dependent upon insect pollinators, resulting in interspecific evolutionary influences, with orchid mimicry being a conspicuous example. The fact that exaggerated or supernormal stimuli tend to be preferred may be due in part to the nature of the sensory system. Whereas more intense stimuli may elicit a greater response, sensory mechanisms for measuring the absolute intensity of a stimulus may be lacking. The fact that responses are elicited by stimuli of different intensities can have an adaptive significance, since the flexibility of the response may be beneficial in the event of environmental or evolutionary changes. On the other hand, many examples are reported in the literature of the fact that responses to supernormal stimuli can become an evolutionary trap, particularly if changes occur in the habitat. It would therefore be expected that for accurate signal interpretation, it could be beneficial for more than one signal to be used. Examples of such reinforcing combinations of signals can be seen, for instance, in butterfly intersexual communication, where conspicuous coloration and UV markings visible only from a restricted angle serve as signals, and where different signals are provided and received by both the male and female.

In summary, although insect responses to supernormal visual stimuli may sometimes have negative consequences, the fact that absolute signal intensities do not seem to be necessary to elicit a response is advantageous in providing flexibility and adaptability to insect signal and response systems, and in many cases the interaction of a combination of signals can help to ensure an adaptive response.

ACKNOWLEDGEMENTS. I am grateful to H. Hull III (San Vito, Costa Rica) and E. John (Cowbridge, UK) for kindly allowing the use of their photographs. Many thanks to M. Ansell (Halifax, Canada) for providing helpful comments and correction of the English text in the manuscript submitted for publication. I would also like to thank the referees for their valuable suggestions, which have significantly improved the quality of the manuscript.

\section{REFERENCES}

Agrawal S., Safarik S. \& Dickinson M. 2014: The relative roles of vision and chemosensation in mate recognition of Drosophila melanogaster. - J. Exp. Biol. 217: 2796-2805. 
ARIKAWA K. \& Uchiyama H. 1996: Red receptors dominate the proximal tier of the retina in the butterfly Papilio xuthus. $-J$. Comp. Physiol. (A) 178: 55-61.

Barrows E.M. 2011: Animal Behavior Desk Reference: A Dictionary of Animal Behavior, Ecology, and Evolution. 3rd ed. CRC Press, Taylor \& Francis Group, Boca Raton, London, New York, 800 pp.

Benitez-Vieyra S., Medina A.M. \& Cocucci A.A. 2009: Variable selection patterns on the labellum shape of Geoblasta pennicillata, a sexually deceptive orchid. - J. Evol. Biol. 22 2354-2362.

Bernáth B., Szedenics G., Molnár G., Kriska G. \& Horváth G. 2001: Visual ecological impact of "shiny black anthropogenic products" of aquatic insects: oil reservoirs and plastic sheets as polarized traps for insects associated with water. - Arch. Nat.-Lands. 40: 89-109.

Boeddeker N., Kern R. \& EgelhaAf M. 2003: Chasing a dummy target: smooth pursuit and velocity control in male blowflies. - Proc. R. Soc. Lond. (B) 270: 393-399.

Bohman B., Karton A., Dixon R.C.M., Barrow R.A. \& Peakall R. 2016: Parapheromones for thynnine wasps. - J. Chem. Ecol. 42: 17-23.

BraKefield P.M. \& French V. 1999: Butterfly wings: the evolution of development of colour patterns. - BioEssays 21 : 391-401.

BRower A.V.Z. 1994: Rapid morphological radiation and convergence among races of the butterfly Heliconius erato inferred from patterns of mitochondrial DNA evolution. - Proc. Natn. Acad. Sci. U.S.A. 91: 6491-6495.

BROWN K.S. JR. 1981: The biology of Heliconius and related genera. - Annu. Rev. Entomol. 26: 427-456.

Chakravarthy M.V. \& Booth F.W. 2004: Eating, exercise, and "thrifty" genotypes: Connecting the dots toward an evolutionary understanding of modern chronic diseases. - J. Appl. Physiol. 96: 3-10.

ChittKa L., Shmida A., Troje N. \& Menzel R. 1994: Ultraviolet as a component of flower reflections, and the colour perception of Hymenoptera. - Vision Res. 34: 1489-1508.

Chittka L., Dyer A.G., Bock F. \& Dornhaus A. 2003: Psychophysics: Bees trade off foraging speed for accuracy. - Nature (London) 424: 388.

CowAN T. \& Gries G. 2009: Ultraviolet and violet light: attractive orientation cues for the Indian meal moth, Plodia interpunctella. - Entomol. Exp. Appl. 131: 148-158.

Cresswell J.E. \& Galen C. 1991: Frequency-dependent selection and adaptive surfaces for floral character combinations - the pollination of Polemonium viscosum. - Am. Nat. 138: 1342-1353.

Dafni A., Lehrer M. \& Kevan P.G. 1997: Spatial flower parameters and insect spatial vision. - Biol. Rev. 72: 239-282.

DARwIN C.R. 1862: On the Various Contrivances by which British and Foreign Orchids are Fertilised by Insects, and on the Good Effects of Intercrossing. 1st ed., Vol. 1. John Murray, London, $336+32 \mathrm{pp}$.

DAumer K. 1958: Blumenfarben, wie sie die Bienen sehen. $-Z$. Vergl. Physiol. 41: 49-110.

De JAGER M.L. \& Peakall R. 2016: Does morphology matter? An explicit assessment of floral morphology in sexual deception. - Funct. Ecol. 30: 537-546.

Dinkel T. \& LunAu K. 2001: How drone flies (Eristalis tenax L., Syrphidae, Diptera) use floral guides to locate food sources. J. Insect Physiol. 47: 1111-1118.

Douglas J.M., Cronin T.W., Chiou T.-H. \& Dominy N.J. 2007: Light habitats and the role of polarized iridescence in the sen- sory ecology of neotropical nymphalid butterflies (Lepidoptera: Nymphalidae). - J. Exp. Biol. 210: 788-799.

Eguchi E. \& Meyer-Rochow W.B. 1983: Ultraviolet photography of forty-three species of Lepidoptera representing ten families. - Annot. Zool. Japon. 56: 10-18.

ENQUIST M. \& ARAK A. 1994: Symmetry, beauty and evolution. Nature (London) 372: 169-172.

Galen C. \& NewPort M.E.A. 1987: Bumble bee behaviour and selection on flower size in the sky pilot Polemonium viscosum. - Oecologia 74: 20-23.

Gaskett A.C., Winnick C.G. \& Herberstein M.E. 2008: Orchid sexual deceit provokes ejaculation. - Am. Nat. 171: E206E212.

Gaskett A.C. 2011: Orchid pollination by sexual deception: pollinator perspectives. - Biol. Rev. Camb. Philos. Soc. 86: 33-75.

Giurfa M., Eichmann B. \& Menzel R. 1996: Symmetry perception in an insect. - Nature (London) 382: 458-461.

Giurfa M., DafNi A. \& NeAl P.R. 1999: Floral symmetry and its role in plant-pollinator systems. - Int. J. Plant Sci. (Suppl. 6) 160: S41-S50.

Gómez J.M., Bosch J., Perfectti F., Fernández J.D., Abdelaziz M. \& САмасно J.P.M. 2008: Spatial variation in selection on corolla shape in a generalist plant is promoted by the preference patterns of its local pollinators. - Proc. R. Soc. Lond. (B) 275: 2241-2249.

Goodwin B.C., Browne M. \& Rockloff M. 2015: Measuring preference for supernormal over natural rewards: a two-dimensional anticipatory pleasure scale. - Evol. Psychol. 13 (doi: 10.1177/1474704915613914), $11 \mathrm{pp}$.

Goulson D. 2012: Bumblebees. Behaviour, Ecology and Conservation. Oxford University Press, Oxford, $317 \mathrm{pp}$.

Guldberg L.D. \& Atsatt P.R. 1975: Frequency of reflection and absorption of ultraviolet light in flowering plants. - Am. Midl. Nat. 93: 35-43.

Gwynne D.T. \& Rentz D.C.F. 1983: Beetles on the bottle: Male buprestids mistake stubbies for females (Coleoptera). - Aust. J. Entomol. 22: 79-80.

HARDY I.C.W. 1994: Sex ratio and mating structure in the parasitoid Hymenoptera. - Oikos 69: 3-20.

HAWKESWOOD T.J. 2005: Review of the biology and host-plants of the Australian jewel beetle Julodimorpha bakewelli (White, 1859) (Coleoptera: Buprestidae). - Calodema 3: 3-5.

HeinRICH B. 1979: Bumblebee Economics. Harvard University Press, Cambridge, MA, 288 pp.

Horovitz A. \& CoHEN Y. 1972: Ultraviolet reflectance characteristics in flowers of crucifers. - Am. J. Bot. 59: 706-713.

HorRIDGE G.A. 1996: The honeybee (Apis mellifera) detects bilateral symmetry and discriminates its axis. - J. Insect Physiol. 42: 755-764.

Horváth G., Kriska G., Malik P. \& Robertson B. 2009: Polarized light pollution: a new kind of ecological photopollution. -Front. Ecol. Environ. 7: 317-325.

IMAFUKU M. \& KitAMURA T. 2015: Ability of males of two theclini species (Lepidoptera: Lycaenidae) to discriminate between sexes and different types of females based on the colour of their wings. - Eur. J. Entomol. 112: 328-333.

Immelmann K. \& Beer C. 1992: A Dictionary of Ethology. Harvard University Press, Cambridge, MA, 352 pp.

Jersáková J., Johnson S.D. \& KindLMAnN P. 2006: Mechanisms and evolution of deceptive pollination in orchids. - Biol. Rev. Camb. Philos. Soc. 81: 219-235.

JersákovÁ J., JuRgens A., Šmilauer P. \& Johnson S.D. 2012: The evolution of floral mimicry: identifying traits that visually attract pollinators. - Funct. Ecol. 26: 1381-1389. 
JoHNSON S.D. \& ANDERSSON S. 2002: A simple field method for manipulating ultraviolet reflectance of flowers. - Can. J. Bot. 80: $1325-1328$.

KEMP D.J. 2007: Female butterflies prefer males bearing bright iridescent ornamentation. - Proc. R. Soc. Lond. (B) 274 1043-1047.

Kenward B., Wachtmeister C.-A., Ghirlanda S. \& Enquist M. 2004: Spots and stripes: the evolution of repetition in visual signal form. - J. Theor. Biol. 230: 407-419.

Kinoshita M., TaKahashi Y. \& ARIKaWA K. 2008: Simultaneous color contrast in the foraging swallowtail butterfly, Papilio $x u$ thus. - J. Exp. Biol. 211: 3504-3511.

Koshitaka H., Kinoshita M., Vorobyev M. \& Arikawa K. 2008: Tetrachromacy in a butterfly that has eight varieties of spectral receptors. — Proc. R. Soc. Lond. (B) 275: 947-954.

Koski M.H. \& Ashman T.-L. 2014: Dissecting pollinator responses to a ubiquitous ultraviolet floral pattern in the wild. - Funct. Ecol. 28: 868-877.

Kullenberg B. 1961: Studies in Ophrys pollination. - Zool. Bidr. (Uppsala) 34: 1-340.

LAND M. 1997: Visual acuity in insects. - Annu. Rev. Entomol. 42: $147-177$.

LEA A.M. \& RYAN M.J. 2015: Irrationality in mate choice revealed by túngara frogs. - Science 349: 964-966.

LuNDGREN L. 1977: The role of intra- and interspecific male : male interactions in Polyommatus icarus Rott. and some other species of blues (Lycaenidae). - J. Res. Lepid. 16: 249-264.

LyNn S.K., CNAANi J. \& PAPAJ D.R. 2005: Peak shift discrimination learning as a mechanism of signal evolution. - Evolution 59: $1300-1305$.

MAgnus D. 1958: Experimentelle Untersuchungen zur Bionomie und Ethologie des Kaisermantels Argynnis paphia L. (Lep. Nymph.). I. Über optische Auslöser von Anfliegereaktionen und ihre Bedeutung für das Sichfinden der Geschlechter $-Z$. Tierpsychol. 15: 397-426.

Matthews R.W. \& Matthews J.R. 1978: Insect Behavior. John Wiley \& Sons, New York, Chichester, Brisbane, Toronto, 507 pp.

Menzel R. \& ERber I. 1978: Learning and memories in bees. Sci. Am. 239: 102-110.

Merry J.W., Morehouse N.I., Yturralde K. \& Rutowski R.L. 2006: The eyes of a patrolling butterfly: visual field and eye structure in the Orange Sulphur, Colias eurytheme (Lepidoptera, Pieridae). - J. Insect Physiol. 52: 240-248.

Meyer-Rochow V.B. 1991: Differences in ultraviolet wing patterns in the New Zealand lycaenid butterflies Lycaena salustius, L. rauparaha, and L. feredayi as a likely isolating mechanism. - J. R. Soc. N. Z. 21: 169-177.

MeYer-Rochow V.B. \& JärVILEhto M. 1997: UV-colours in Pieris napi from northern and southern Finland: Arctic females are the brightest. - Naturwissenschaften 84: 165-168.

Møller A.P. \& ERIKsson M. 1994: Patterns of fluctuating asymmetry in flowers: Implications for sexual selection in plants. —J. Evol. Biol. 7: 97-113.

Møller A.P. \& ERIKSSON M. 1995: Pollinator preference for symmetrical flowers. - Proc. Natn. Acad. Sci. U.S.A. 92: 22882292.

MølLER A.P. \& SoRCI G. 1998: Insect preference for symmetrical artificial flowers. - Oecologia 114: 37-42.

NeAl P.R., DafNi A. \& GiURFA M. 1998: Floral symmetry and its role in plant-pollinator systems: terminology, distribution, and hypotheses. - Annu. Rev. Ecol. Syst. 29: 345-373.

NiLSSON L.A. 1979: Anthecological studies on the lady's slipper, Cypripedium calceolus (Orchidaceae). - Bot. Not. 132 329-347.
Ohara M. \& Higashi S. 1994: Effects of inflorescence size on visits from pollinators and seed set of Corydalis ambigua (Papaveraceae). - Oecologia 98: 25-30.

PALMER A.R. 1996: Waltzing with asymmetry. - Bioscience 46: 518-532.

Paulus H.F. 1997: Signale in der Bestäuberanlockung: Weibchenimitation als Bestäubungsprinzip bei der mediterranen Orchideengattung Ophrys. - Verh. Zool. Bot. Ges. Österr. 134: 133-176.

Perry C.J. \& Barron A.B. 2013: Neural mechanisms of reward in insects. - Annu. Rev. Entomol. 58: 543-562.

Robertson B.A., Rehage J.S. \& SiH A. 2013: Ecological novelty and the emergence of evolutionary traps. - Trends Ecol. Evol. 28: $552-560$.

Rodriguez I., Gumbert A., de Ibarra N.H., Kunze J. \& Giurfa M. 2004: Symmetry is in the eye of the "beeholder": innate preference for bilateral symmetry in flower-naive bumblebees. - Naturwissenschaften 91: 374-377.

Russell E.S. 1943: Perceptual and sensory signs in instinctive behavior. - Proc. Linn. Soc. Lond. 154: 195-216.

RUTOWSKI R.L. 1977: The use of visual cues in sexual and species discrimination by males of the small sulphur butterfly Eurema lisa (Lepidoptera, Pieridae). - J. Comp. Physiol. 115: 61-74.

Rutowski R.L. 2003: Visual Ecology of Adult Butterflies. In Boggs C.L., Watt W.B. \& Ehrlich P.R. (eds): Butterflies: Ecology and Evolution Taking Flight. University of Chicago Press, Chicago, pp. 9-25.

Rutowski R.L., Mccoy L. \& Demlong M.J. 2001: Visual mate detection in a territorial male butterfly (Asterocampa leilia): Effects of distance and perch location. - Behaviour 138: 31-43.

RUTOWSKI R.L. \& WARRANT E.J. 2002: Visual field structure in the Empress Leilia, Asterocampa leilia (Lepidoptera, Nymphalidae): dimensions and regional variation in acuity. $-J$. Comp. Physiol. (A) 188: 1-12.

Rutowski R.L., Macedonia J.M., Merry J.W., Morehouse N.I., Yturralde K., Taylor-Taft L., Gaalema D., Kemp D.J. \& PAPKE R.S. 2007: Iridescent ultraviolet signal in the orange sulphur butterfly (Colias eurytheme): spatial, temporal and spectral properties. - Biol. J. Linn. Soc. 90: 349-364.

SChlaepfer M.A., Runge M.C. \& Sherman P.W. 2002: Ecological and evolutionary traps. - Trends Ecol. Evol. 17: 474-480.

Silberglied R.E. 1977: Communication in the Lepidoptera. In Sebeok T.A. (ed.): How Animals Communicate. Indiana University Press, Bloomington, pp. 362-402.

SilBergLied R.E. 1984: Visual communication and sexual selection among butterflies. In Vane-Wright R., Ackery P. \& DeVries P. (eds): The Biology of Butterflies. Academic Press, London, pp. 207-223.

Spaethe J., Moser W.H. \& Paulus H.F. 2007: Increase of pollinator attraction by means of a visual signal in the sexually deceptive orchid, Ophrys heldreichii (Orchidaceae). - Plant Syst. Evol. 64: 31-40.

Srinivasan M.V., Zhang S.W. \& Rolfe B. 1993: Pattern vision in insects: "cortical" processing? - Nature (London) 362: 539-540.

SRinivasan M.V., Zhang S.W. \& Whitney K. 1994: Visual discrimination of pattern orientation by honeybees. - Philos. Trans. R. Soc. Lond. (B) 343: 199-210.

STADDON J.E.R. 1975: A note on the evolutionary significance of "supernormal" stimuli. — Am. Nat. 109: 541-445.

Stavenga D.G., Kinoshita M., Yang E.C. \& Arikawa K. 2001: Retinal regionalization and heterogeneity of butterfly eyes. Naturwissenschaften 88: 477-481. 
SweEney A., Jiggins C. \& JohnSEN S. 2003: Insect communication: polarized light as a butterfly mate signal. - Nature (London) 423: 31-34.

TEN CATE C. \& Rowe C. 2007: Biases in signal evolution: Learning makes a difference. - Trends Ecol. Evol. 22: 380-387.

Tinbergen N. 1948: Social releasers and the experimental method required for their study. - Wilson Bull. 60: 6-51.

Tinbergen N. 1951: The Study of Instinct. Clarendon Press, Oxford, $228 \mathrm{pp}$.

Tricca G. \& Trujillo-Cenóz O. 1980: The sexual behavior of the robber-fly Mallophora ruficauda Wied. (Asilidae, Asilinae) in normal and experimental conditions. - Physiol. Behav. 25: $627-632$.

VereeCKen N.J. \& SChiestl F.P. 2008: The evolution of imperfect floral mimicry. — Proc. Natn. Acad. Sci. U.S.A. 105: 7484 7488.

Vogel G. 1957: Verhaltensphysiologische Untersuchungen über die den Weibchenbesprung des Stubenfliegen-Männchens (Musca domestica) auslösenden optischen Faktoren. - Z . Tierpsychol. 14: 309-323.

Vogel G. 1958: Supernormale Auslösereize bei Sarcophaga carnaria (Dipt.). — Zool. Beitr. 4: 69-76.
Wasik B.R., Liew S.F., Lilien D.A., Dinwiddie A.J., NoH H., CAO H. \& Monteiro A. 2014: Artificial selection for structural color on butterfly wings and comparison with natural evolution. Proc. Natn. Acad. Sci. U.S.A. 111: 12109-12114.

WeLSFORD M.R. \& Johnson S.D. 2012: Solitary and social bees as pollinators of Wahlenbergia (Campanulaceae): single-visit effectiveness, overnight sheltering and responses to flower color. - Arthropod-Plant Interact. 6: 1-14.

White T.E., ZeIL J. \& Kemp D.J. 2015: Signal design and courtship presentation coincide for highly biased delivery of an iridescent butterfly mating signal. - Evolution 69: 14-25.

WiKLUND C. 2003: Sexual selection and the evolution of butterfly mating systems. In Boggs C.L., Watt W.B. \& Ehrlich P.R. (eds): Butterflies. Ecology and Evolution Taking Flight. The University of Chicago Press, Chicago, pp. 67-90.

Wong B.B.M. \& Schiestl F.P. 2002: How an orchid harms its pollinator. - Proc. R. Soc. Lond. (B) 269: 1529-1532.

Zaccardi G., Kelber A., Sison-Mangus M.P. \& Briscoe A.D. 2006: Color discrimination in the red range with only one longwavelength sensitive opsin. - J. Exp. Biol. 209: 1944-1955.

ZiegLer C. 2011: Deceptive Beauties. The World of Wild Orchids. The University of Chicago Press, Chicago, London, 184 pp.

Received March 12, 2016; revised and accepted June 13, 2016 Published online August 9, 2016 